\title{
A PROIBIÇÃO DE PATENTES PARA OS MEDICAMENTOS CONTRA A AIDS NA LEGISLAÇÃO PÓS-OMC E SUAS CONSEQÜÊNCIAS NO ÂMBITO DO TRIPS/OMC
}

Henrique da Silva Mercer ${ }^{1}$

\section{RESUMO}

Se for aprovado pelo Congresso Nacional o projeto de lei apresentado pelo deputado Roberto Gouvêa que visa a tornar não-patenteáveis os medicamentos específicos para a prevenção e o tratamento da AIDS, o resultado poderá ser prejudicial para o Brasil em muitos aspectos, notadamente em relação à coibição de abusos econômicos, comprometendo interesses do País junto ao o TRIPS (Agreement on Trade-Related Aspects of Intellectual Property Rights - Acordo sobre Direitos de Propriedade Intelectual Relacionados com o Comércio). Pode-se apontar no projeto, pelo menos três ordens de imperfeição: desacordo com a técnica legislativa, forma simplista de tratar o complexo mundo da farmacologia e inobservância de tratado internacional livremente aceito, com a permissão a indústrias locais de fabricar versões genéricas de medicamentos cuja fórmula é protegida por patente. $O$ objetivo do presente trabalho é conduzir uma análise do projeto à luz do TRIPS.

\section{ABSTRACT}

The present article aims to demonstrate the possible consequences concerning the approval of law project 22/2003 by Congressman Roberto Gouvêa on course in the National Congress. The objective of such project is to prohibit the registration of patents of drugs used in the prevention and the treatment of AIDS. Once approved, this law project might bring disastrous

\footnotetext{
${ }^{1}$ Coordenador Jurídico da Casa Latino-Americana, CASLA.
}

Revista Brasileira de Direito Internacional, Curitiba, v.4, n.4, jul./dez.2006 
consequences to Brazil, especially in relation to economic abuses, which will jeopardize Brazilian interests towards TRIPS (Agreement on Trade-Related Aspects of Intellectual Property Rights). At least three serious imperfections can be pointed out: misapplication of legislative technique; the approach to the complex world of pharmacology without questioning its rightness; and disregard for a widely accepted international treaty, which is triggered by local factories production of generic versions of drugs whose formula is protected by patent.

Palavras-chave: projeto de lei, medicamentos, AIDS, TRIPS.

Key-words: law project, medicaments, AIDS, TRIPS.

\section{INTRODUÇÃo}

Encontra-se em tramitação no Congresso Nacional projeto de lei 22/2003, de autoria do deputado Roberto Gouvêa (PT-SP), que tem por objeto tornar não-patenteáveis os medicamentos específicos para a prevenção e o tratamento da AIDS. A proposta é merecedora de atenção não apenas por seu alcance em termos de saúde pública, mas também, por seus desdobramentos no plano do Direito Internacional. O presente trabalho tem por objetivo analisar esse projeto à luz do TRIPS, procurando antecipar as conseqüências que adviriam de sua aprovação para o Brasil enquanto Estado filiado à OMC.

\section{O PROJETO DE LEI}

Em sua materialidade legal, o projeto limita-se a incluir um inciso ao artigo 18 da Lei n. 9.279 , de 14 de maio de 1996, que regula direitos e obrigações relativos à propriedade industrial. $\mathrm{O}$ artigo 18 arrola em três incisos os objetos que não podem ser patenteados ${ }^{2}$, aos quais adiciona o seguinte: "IV

\footnotetext{
2 "Art. 18. Não são patenteáveis:

I - o que for contrário à moral, aos bons costumes e à segurança, à ordem e à saúde públicas;

II - as substâncias, matérias, misturas, elementos ou produtos de qualquer espécie, bem como a modificação de suas propriedades físico-químicas e os respectivos processos de obtenção ou modificação, quando resultantes de transformação do núcleo atômico; e
}

Revista Brasileira de Direito Internacional, Curitiba, v.4, n.4, jul./dez.2006 
- o medicamento, assim como seu respectivo processo de obtenção, específico para a prevenção e o tratamento da Síndrome de Imunodeficiência Adquirida - SIDA/AIDS".

Alega o deputado que o mundo atualmente vem enfrentado uma pandemia de AIDS, que mata milhões de pessoas por ano, principalmente na áfrica subsariana. No Brasil, segundo a justificativa do projeto, existiriam aproximadamente 600 mil portadores do $\mathrm{HIV}^{3}$.

Os gastos do Governo Federal com medicamentos anti-retovirais vêm crescendo anualmente ${ }^{4}$, inclusive devido aos preços praticados pelos fabricantes. Numa situação como essa, não se poderia ficar à mercê dos altos preços dos remédios que fazem parte do tratamento da AIDS, que custam caro tanto para os doentes como para o Governo.

A justificativa para o projeto está em que a lei, na forma atual, pode levar o detentor da patente a praticar abuso econômico ou comercial, amparado no próprio texto legal. O ramo industrial mais apto a praticar esses abusos seria o setor farmacêutico.

O projeto de lei teria por objetivo:

\begin{abstract}
A possibilidade de indústrias locais produzirem medicamentos intercambiáveis. O produto intercambiável é o equivalente terapêutico de medicamento inovador ou de referência. O País precisa tratar seus doentes da forma mais eficiente possível. Se for permitido ao interessado local produzir o genérico, e seguramente o preço de venda será menor que o medicamento de marca, e assim, estaremos, no futuro, sendo mais eficientes que no presente: remédios menos caros, menores despesas com saúde pública e mais postos de empregos oferecidos. ${ }^{5}$
\end{abstract}

III - o todo ou parte dos seres vivos, exceto os microorganismos transgênicos que atendam aos três requisitos de patenteabilidade - novidade, atividade inventiva e aplicação industrial previstos no art. $8^{\circ}$ e que não sejam mera descoberta.

Parágrafo único. Para os fins desta Lei, microorganismos transgênicos são organismos, exceto o todo ou parte de plantas ou de animais, que expressem, mediante intervenção humana direta em sua composição genética, uma característica normalmente não alcançável pela espécie em condições naturais".

${ }^{3}$ Atualmente 170 mil pacientes são atendidos pela distribuição gratuita de medicamentos do Programa DST/AIDS do Governo Federal (PORFÍRIO, Fernando. Justiça condena laboratório indiano por quebra de patente. Revista Consultor Jurídico, 22 set. 2005).

${ }_{4}^{4}$ Devem chegar a $\mathrm{R} \$ 950$ milhões esse ano.

${ }^{5}$ BRASIL. Presidência da República. Lei no 9.279, de 14 de maio de 1996. [Online]. Disponível em: <https://www.planalto.gov.br/ccivil_03/Leis/L9279.htm>. Acesso em: 10 ago. 2004.

Revista Brasileira de Direito Internacional, Curitiba, v.4, n.4, jul./dez.2006 
Por fim, o deputado explica que baseou seu projeto numa lei sulafricana de 2001, que "permite que empresas locais produzam versões genéricas de drogas patenteadas para a AIDS, ou as importem de países onde sejam mais baratas. Existe, como seria de esperar, reações de fabricantes multinacionais (sic)"6.

Ainda na fase inicial de tramitação do processo, o Legislativo foi alertado pelo Ministério das Relações Exteriores de que o projeto de lei em tela era incompatível com as obrigações internacionais do Brasil. ${ }^{7}$ Ainda assim, a Comissão de Constituição e Justiça da Câmara - CCJ o aprovou em $1 . .9$ de junho do corrente ano sob o argumento de que "os interesses de saúde pública e da vida estão acima dos direitos industrias"

Após a aprovação do projeto na CCJ, foi aberto prazo para apresentação de recursos. Dois deputados ${ }^{9}$ apresentaram pedido de que o projeto fosse votado em plenário. O prazo encerrou no dia 21 de junho. Depois de sanada a questão dos recursos na Câmara, o projeto seguirá para o Senado.

Embora sejam compreensíveis suas motivações, a proposta em tela padece de ao menos três graves imperfeições. A primeira, que salta aos olhos, é a de técnica legislativa: por que limitar o escopo da não-patenteabilidade aos remédios estritamente destinados à AIDS? A lei, é bem sabido, deve buscar a máxima generalidade. Graun-Kuntz adverte que é descabido vincular "medidas voltadas a restringir o direito de patentes a um determinado catálogo de moléstias específicas e/ou em grau de disseminação"10 acaba por agredir a noção de dignidade humana. Se os motivos que militam a favor da AIDS são a extensão da epidemia e o alto custo que representa para a saúde pública, tais aspectos podem apresentar-se em outros casos. Já não se fala em recrudescimento da tuberculose, com cepas cada vez mais resistente aos

\footnotetext{
${ }^{6}$ BRASIL. Câmara dos Deputados. Projeto de Lei no 22, de 2003. [Online]. Disponível em: $<$ http://www.abiaids.org.br/media/pl\%202203.pdf>. Acesso em: nov. 2006.

7 O ESTADO DE SÃO PAULO, 24 jun. 2005.

${ }^{8}$ O ESTADO DE SÃO PAULO. O preço da bravata. Editorial. 13 jun. 2005.

${ }^{9}$ Recurso no 192/2005, do Dep. Benedito Dias e Recurso no 195/2005, do Dep. Ronaldo Dimas.

${ }^{10}$ GRAU-KUNTZ, Karin. Dignidade humana e direito de patentes: sobre o problema do acesso a medicamentos. In: CARVALHO, Patrícia Luciane. (Coord.). Propriedade intelectual: estudos em homenagem à professora Maristela Basso. Curitiba: Juruá, 2005. p. 314.
}

Revista Brasileira de Direito Internacional, Curitiba, v.4, n.4, jul./dez.2006 
antibióticos disponíveis? O texto deveria abranger, portanto, medicamentos destinados a qualquer doença em caso de surto epidêmico cujo controle importe em custo excessivos para as autoridades públicas.

Uma segunda deficiência reside na forma simplista de tratar 0 complexo mundo da farmacologia. Se uma simples lei pudesse ter o efeito de baratear remédios, haveria bons motivos para acusar de crime contra a saúde pública todos os políticos que não tiveram desde cedo essa iniciativa. O ganho financeiro é um estímulo insubstituível para a pesquisa e para a produção de novos remédios. Tanto assim é que os grandes laboratórios são com freqüência acusados de não se dedicarem à malária porque a grande maioria de suas vítimas se concentra em países pobres ${ }^{11}$.

Aliás, os laboratórios estrangeiros que colaboram com o programa antiAIDS do governo brasileiro através de licenças voluntárias desde já ficam em compasso de espera, sem evoluir na liberação de novas patentes ${ }^{12}$, colocando em risco aquelas patentes que já foram concedidas voluntariamente, e aquelas que não foram licenciadas, mas cujos fabricantes reduziram o preço ${ }^{13}$.

\footnotetext{
${ }^{11}$ Nos últimos 25 anos foram desenvolvidos mais de 100 medicamentos contra doenças cardíacas, ao passo que no mesmo período não foram desenvolvidos mais do que uma dúzia de medicamentos contra doenças típicas de países (populações) pobres, tais como malária, chagas, etc., cujas vítimas em sura maioria, não tem como pagar pelo tratamento, tão pouco seus governos, o que vai contra a lógica do lucro (GRAU-KUNTZ, Karin. Dignidade humana e direito de patentes: sobre o problema do acesso a medicamentos. In: CARVALHO, Patrícia Luciane. (Coord.). Propriedade intelectual: estudos em homenagem à professora Maristela Basso. Curitiba: Juruá, 2005. p. 309). Como afirma Vargas, a pesquisa farmacêutica não é atividade filantrópica e "é um erro atribuir ao mercado a função de suprir as demandas de saúde pública". (VARGAS, Fábio Aristimunho. O regime internacional de proteção do acesso a medicamentos: um enfoque social. In: CARVALHO, Patrícia Luciane. (Coord.). Propriedade intelectual: estudos em homenagem à professora Maristela Basso. Curitiba: Juruá, 2005. p. 318).

${ }^{12}$ O Ministério da Saúde vem negociando para obtenção da licença voluntária de três drogas (Lopinavir/Ritonavir, Tenofovir e Efavirenz) que fazem parte do coquetel anti-AIDS e juntas representam $70 \%$ dos gastos do Governo com drogas contra a doença. (MÉDICOS sem fronteiras. [Online]. Disponível em: <http://www.msf.org.br>. Acesso em: 17 jul. 2005). Só com a compra de Kaletra, medicamento produzido pelo laboratório norte-americano Abbott com 0 principio ativo Lopinavir, consumido por 23,4 mil pacientes do Programa DST/AIDS do Governo Federal, serão gastos esse ano $\mathrm{R} \$ 257$ milhões. No caso desse medicamento, a expectativa do Ministério as Saúde com o acordo é baixa o preço unitário de US\$1,17 para US $\$ 0,49$ (PORFÍRIO, Fernando. Justiça condena laboratório indiano por quebra de patente. Revista Consultor Jurídico, 22 set. 2005).

${ }^{13} \mathrm{O}$ Governo brasileiro tem conseguido uma redução que chega a $65 \%$ do preço dos medicamentos (O GLOBO, $21 \mathrm{dez}$. 2004).
} 
No campo das patentes industriais, há grandes interesses em jogo. Tão grandes que são protegidos pelos governos nacionais. Assim é que já se vislumbra outra conseqüência:

\begin{abstract}
É a campanha deflagrada por cinco deputados republicanos e pelo exsecretário de Defesa Frank Carlucci para que o governo Bush recoloque o tema da proteção da propriedade intelectual entre as prioridades da agenda bilateral com o Brasil. O objetivo é persuadir o representante comercial da Casa Branca, Robert Portman ${ }^{14}$, a aproveitar a próxima etapa do processo de revisão das isenções tarifárias concedidas ao Brasil sob o Sistema Geral de Preferências, marcada para setembro ${ }^{15}$, para fazer retaliações. Essas isenções, que beneficiaram cerca de $10 \%$ das exportações brasileiras para os EUA em 2004, no valor de aproximadamente US\$ 2,5 bilhões, começaram a ser revistas com o objetivo de pressionar o País a combater com maior rigor a pirataria de vídeos, CDs e outros produtos eletrônicos. O detalhe é que esse sistema de preferências e isenções é unilateral. Ou seja, é uma liberalidade que o governo americano se dá ao direito de promover, em matéria de política de importações. ${ }^{16}$
\end{abstract}

Se a aprovação desse projeto tiver concorrido para as retaliações, quem estará pagando o preço da fatura serão os empresários brasileiros que se esforçam na disputa do mercado americano e os seus funcionários, cujos empregos estarão em risco.

A terceira imperfeição do projeto já foi sinalizada pelo Itamaraty. Se o projeto for aprovado e entrar em vigor, a lei permitirá que indústrias locais produzam versões genéricas de medicamentos que têm sua fórmula protegida por patente. Com isso, o Estado brasileiro estará violando o TRIPS. ${ }^{17}$

O Acordo TRIPS, cabe recordar, compõe o Anexo 1-C do Acordo Geral da OMC e tem por objetivo completar as deficiências do sistema da Organização Mundial da Propriedade Intelectual (OMPI) e vincular definitivamente os direitos de propriedade intelectual ao comércio internacional. Suas disposições constituem padrões mínimos de proteção que devem ser adotados pelos Estados-Parte em suas legislações nacionais. Para o TRIPS, o

\footnotetext{
${ }^{14}$ Em um oficio ao embaixador brasileiro em Whashington, Portman lembrou que o Brasil está na "lista de 'observação' dos EUA de países que não protegem a propriedade intelectual" (O ESTADO DE SÃO PAULO. O preço da bravata. Editorial. 13 jun. 2005).

${ }^{15}$ Dia 30 de setembro (CRELIER, Cristiane. Brasil mostra relatório contra pirataria. Gazeta Mercantil, Caderno A, São Paulo, p. 12, 31 ago. 2005).

${ }_{17}^{16}$ O ESTADO DE SÃO PAULO, 24 jun. 2005.

17 As obrigações advindas do ingresso na OMC implicam em que os estados-membros não violem o Acordo Constitutivo, do qual o TRIPS faz parte.
}

Revista Brasileira de Direito Internacional, Curitiba, v.4, n.4, jul./dez.2006 
termo propriedade intelectual indica todas as categorias de propriedade intelectual: direito do autor e direitos conexos, marcas, indicações geográficas, desenhos indústrias, patentes, topografia de circuitos integrados e proteção de informação confidencial $^{18}$.

O Acordo, naturalmente, prevê a patenteabilidade de fármacos. Ressalte-se que não existe patente internacional; a concessão de patente é o ato soberano de cada Estado. E o Brasil decidiu soberanamente aderir ao TRIPS e permitir o patenteamento de fármacos ${ }^{19}$. Devido ao princípio do single undertaking $^{20}$ adotado pela OMC, denunciar um de seus acordos é o mesmo que denunciar todos os acordos dessa Organização, o que redundaria na exclusão do Brasil.

O autor do projeto em tela, além de descurar o risco de o Brasil vir a ser excluído da OMC, não leva em conta que se pode obter resultado muito próximo do desejado, servindo-se de recurso previsto no próprio TRIPS. Tratase da licença compulsória ${ }^{21}$, autorizada pelo TRIPS e pela legislação brasileira. O governo brasileiro inclusive já ameaçou com a possibilidade do licenciamento compulsório como forma de pressão ${ }^{22}$, para a indústria ceder nas negociações

\footnotetext{
${ }^{18}$ BASSO, Maristela. O direito internacional da propriedade intelectual. Porto Alegre: Livraria do Advogado, 2000.

${ }_{19}$ Artigo 27 do Acordo TRIPS. (Decreto Lei no 30, de 15 de dezembro de 1994. Dispõe sobre o Acordo TRIPS ou Acordo ADPIC. [Online]. Disponível em:

<http://www.tralac.org/scripts/content.php?id=1033>. Acesso em: nov. 2006).

${ }^{20}$ Expresso no art. 2.․ , II e III do Acordo Constitutivo da OMC, determina "que não é possível aderir apenas parte dos Acordos, sob pena de quebrar seu equilíbrio e lógica estrutural, exceção feita aos 'Acordos Comerciais Plurilaterais', do Anexo 4.

Deste principio decorre a unidade do sistema, portanto esse princípio não admite que os Estado façam reservas ao se tornarem signatários do Acordo (BASSO, Maristela. O direito internacional da propriedade intelectual. Porto Alegre: Livraria do Advogado, 2000. p. 179).

${ }_{21}$ A licença compulsória, que é a licença de uso sem o consentimento do titular da patente, pode ser concedida sempre que a empresa dona da patente exercer de forma abusiva seus direitos de patente. Em casos de emergência nacional e interesse público também se faculta a concessão de licença compulsória. Dessa forma, o laboratório farmacêutico receberia a título de royalties um quantum considerado justo pelo Estado que licenciou compulsoriamente uma patente de oficio, o que vem sendo denominado de "quebra de patente" pelos laboratórios internacionais produtores de fármacos.

${ }^{22}$ Primeiro com base no artigo 68 e depois com base no art. 71 da lei brasileira de patentes.

"Art. 71. Nos casos de emergência nacional ou interesse público, declarados em ato do Poder Executivo Federal, desde que o titular da patente ou seu licenciado não atenda a essa necessidade, poderá ser concedida, de ofício, licença compulsória, temporária e não exclusiva, para a exploração da patente, sem prejuízo dos direitos do respectivo titular".

Parágrafo único. $O$ ato de concessão da licença estabelecerá seu prazo de vigência e a possibilidade de prorrogação. (BRASIL. Presidência da República. Lei no 9.279, de 14 de maio de 1996. [Online]. Disponível em: <https://www.planalto.gov.br/ccivil_03/Leis/L9279.htm>.
}

Revista Brasileira de Direito Internacional, Curitiba, v.4, n.4, jul./dez.2006 
de preço e para produzir aqui alguns medicamentos, com o aval (licenciamento voluntário) dos detentores da patente, pagando os royalties devidos ${ }^{23}$. Mas nunca chegou autorizar a produção nacional. Se ainda são poucos os casos de efetivo licenciamento compulsório de fármacos entre os membros da OMC, os casos de ameaças de licenciar compulsoriamente um medicamento para tentar baixar o preço do produto não é exclusividade brasileira. Os EUA ameaçaram licenciar compulsoriamente o Cyprobay, produzido pela Bayer e utilizado contra - Anthrax, logo após os atentados do 11 de setembro, conseguindo uma boa redução no preço do produto. Já o Canadá foi mais longe; chegou a licenciar compulsoriamente o Cyprobay e encomendou sua produção a uma concorrente da Bayer, mas logo voltou atrás, conseguindo também uma significativa redução no preço do antibiótico. Afinal, para dispor da propriedade, levado em conta a sua função social (artigo 8 do TRIPS), é necessário garantir a propriedade.

O TRIPS não faz referência à expressão licença compulsória, amplamente utilizada nos direitos internos; opta pela expressão "outros usos sem autorização do titular dos direitos objeto da patente" ${ }^{\text {"24 }}$. Uma licença compulsória pode ser utilizada para permitir que terceiros produzam 0 medicamento de forma a prover o mercado mais rapidamente ou torná-lo mais acessível ao público.

Frisa-se que a lei brasileira foi moldada de conformidade com o TRIPS, uma vez que, a partir da promulgação do Decreto 1.355 de 1994, todos os princípios e tratados pactuados multilateralmente na Rodada do Uruguai começaram a vigorar no Brasil ${ }^{25}$. Por causa disso, o Brasil teve que adaptar

Acesso em: 10 ago. 2004). Cumprem-se assim os requisitos do artigo 31c, h do TRIPS.

${ }^{23}$ UNIVERSIDADE DE SÃO PAULO [Online]. Disponível em: $<$ http://www2.usp.br/canalacontece/frame.php?canal=../canalacontece/\&conteudo=../busca. $p h p$ ? key=compulsório $>$. Acesso em: 10 dez. 2004.

${ }^{24}$ BASSO, Maristela. O direito internacional da propriedade intelectual. Porto Alegre: Livraria do Advogado, 2000.

${ }^{25}$ Quanto à discussão sobre propriedade intelectual em saúde pública, e particularmente sobre a produção de medicamentos, ela tem por patamar legal na OMC o conjunto das disposições sobre patentes, que são objeto de disciplina do TRIPS, pelo disposto na Seção 5 da Parte II, artigos 27 a 34, que devem ser analisadas com as regras das partes 5 e 7 do mesmo Acordo. Segundo o artigo 27, $\S 1^{\circ}$, constitui matéria patenteável qualquer invenção, de produto ou processo, em todos os setores tecnológicos, desde que seja nova e passível de aplicação industrial (MERCADANTE, Araminta; MAGALHÃES, José Carlos (Coord.). Solução e prevenção de litígios internacionais. Rio de Janeiro: Forense, 2003. v. 3).

Revista Brasileira de Direito Internacional, Curitiba, v.4, n.4, jul./dez.2006 
todas as suas leis concernentes à biotecnologia. Esse processo de adaptação não foi linear nem ocorreu pacificamente. Ao contrário, foi extremamente influenciado pelo cenário internacional. $O$ projeto de lei da propriedade intelectual foi enviado ao Congresso em 1991 com pedido de urgência. Apesar disso, só foi aprovado em 1996. Os pontos controvertidos do debate em relação ao projeto de lei referiam-se à inclusão no ordenamento jurídico pátrio da possibilidade de patenteamento de produtos produzidos a partir da química fina e dos biotecnológicos, o que possibilitaria, em última análise, o patenteamento da vida ${ }^{26}$.

Até 1997, quando entrou em vigor a Lei de Patentes, o Brasil não respeitava patentes farmacêuticas internacionais, apoiando-se na Convenção de Paris de $1883^{27}$. A partir daí, as Leis 9.279/96 e 9.456/96 passaram a disciplinar a proteção à biotecnologia ${ }^{28}$, e todos os laboratórios ficaram proibidos de copiar medicamentos até o vencimento do direito de patente, 0 que leva de 15 a 20 anos.

Diante da epidemia de AIDS que se configurou já no final dos anos 80 , o governo brasileiro procurou organizar-se para fazer frente a esse desafio. Em 1993, o Brasil começou a distribuir gratuitamente preservativos e, em 1994, os laboratórios do governo brasileiro, com a ajuda financeira do Banco Mundial, passaram a produzir medicamentos contra a AIDS. Segundo informações de Cruz e Sabóia ${ }^{29}$, quando em 1996 foram alcançados os medicamentos que inibem a multiplicação do vírus no organismo do doente, o Brasil foi um dos primeiros países a distribuí-los gratuitamente, na forma de lei específica. De outro modo, a terapia estaria fora do alcance dos doentes. O preço do coquetel tríplice - um dos principais medicamentos contra a AIDS - varia entre US $\$ 10,000.00$ e US $\$ 15,000.00$ por ano para cada paciente ${ }^{30}$.

\footnotetext{
${ }^{26}$ BARRAL, Weber. O Brasil e a OMC. Curitiba: Juruá, 2002.

${ }^{27}$ LÚCIO, Leandro Araújo (Org.). O Brasil e a OMC: a quebra de patentes de medicamentos contra a AIDS. In: PIMENTEL, Luiz Otávio. Direito Internacional e da Integração. Florianópolis: Fundação Boiteux, 2003.

${ }^{28}$ BARRAL, Weber. O Brasil e a OMC. Curitiba: Juruá, 2002.

${ }^{29}$ CRUZ, Ana Santa; SABOIA, Juliana. O Brasil domou a AIDS. Revista Veja, São Paulo, n. 28 , p. 74-77, fev. 2001.

${ }^{30}$ BS2 Saúde. [Online]. Disponível em: <http://www.maringasaude.com.br>. Acesso em: 07 jan. 2004.
}

Revista Brasileira de Direito Internacional, Curitiba, v.4, n.4, jul./dez.2006 
grande problema do governo brasileiro era, portanto, o preço desses medicamentos, todos importados e protegidos pela lei de patentes. Com isso, o país só poderia comprá-los a preços elevadíssimos. Percebendo que o custo dessas drogas poderia inviabilizar o programa de distribuição gratuita de remédios de AIDS aos portadores do vírus, valeu-se do artigo 68 da Lei 9.279/96 ${ }^{31}$ sobre patentes, elaborada de acordo com o TRIPS, a qual permite 0 licenciamento compulsório em caso de exercício abusivo dos direitos da patente, o que pode ser caracterizado pela ausência de exploração local, nos termos do $\S 1 . \stackrel{\circ}{ }$, I do artigo supramencionado ${ }^{32}$. Sob a alegação de que os remédios para AIDS estavam nessa situação, ameaçou-se licenciar compulsoriamente tais medicamentos para produzi-los sob a forma de genéricos ${ }^{33}$.

\footnotetext{
${ }^{31}$ Art. 68. O titular ficará sujeito a ter a patente licenciada compulsoriamente se exercer os direitos dela decorrentes de forma abusiva, ou por meio dela praticar abuso de poder econômico, comprovado nos termos da lei, por decisão administrativa ou judicial.

$\S 1$ ํ Ensejam, igualmente, licença compulsória:

I - a não exploração do objeto da patente no território brasileiro por falta de fabricação ou fabricação incompleta do produto, ou, ainda, a falta de uso integral do processo patenteado, ressalvados os casos de inviabilidade econômica, quando será admitida a importação; ou II - a comercialização que não satisfizer às necessidades do mercado.

$\S 2^{0}$ A licença só poderá ser requerida por pessoa com legítimo interesse e que tenha capacidade técnica e econômica para realizar a exploração eficiente do objeto da patente, que deverá destinar-se, predominantemente, ao mercado interno, extinguindo-se nesse caso a excepcionalidade prevista no inciso I do parágrafo anterior.

$\S 3$ 3 No caso de a licença compulsória ser concedida em razão de abuso de poder econômico, ao licenciado, que propõe fabricação local, será garantido um prazo, limitado ao estabelecido no art. 74, para proceder à importação do objeto da licença, desde que tenha sido colocado no mercado diretamente pelo titular ou com o seu consentimento.

$\S 4 .^{\circ}$ No caso de importação para exploração de patente e no caso da importação prevista no parágrafo anterior, será igualmente admitida a importação por terceiros de produto fabricado de acordo com patente de processo ou de produto, desde que tenha sido colocado no mercado diretamente pelo titular ou com o seu consentimento.

$\S 5 .^{\circ}$ A licença compulsória de que trata o $\S 1$. somente será requerida após decorridos 3 (três) anos da concessão da patente. (BRASIL.Presidência da República. Lei no 9.279, de 14 de maio de 1996. [Online]. Disponível em: <https://www.planalto.gov.br/ccivil_03/Leis/L9279.htm>. Acesso em: 10 ago. 2004).

${ }^{32} \mathrm{~A}$ obrigação da exploração local era determinada pelo artigo $5 \mathrm{~A}$ da Convenção de Paris. Após a revisão de Haia, "a exploração deixa de ser obrigatória em seu lugar, as leis nacionais podem punir os abusos no exercício do direito, por exemplo, a falta de uso efetivo" (MERCADANTE, Araminta; MAGALHÃES, José Carlos (Coord.). Solução e prevenção de litígios internacionais. Rio de Janeiro: Forense, 2003. p. 236). O TRIPS recepcionou essa disposição em seu artigo 8.․ Portanto, o artigo 31 do TRIPS e a Convenção de Paris são os dispositivos internacionais que regulam a licença compulsória por falta de exploração local.

${ }^{33}$ LA ROCHE, Marie-Catherine de; CIRENZA, Fernanda. AIDS: Esperança e agonia. Revista Marie Claire, São Paulo, p. 90-93, 2003.
} 
Em 8 de junho de 2000, os Estados Unidos apresentaram um questionamento à $\mathrm{OMC}$ quanto à possibilidade de licenciamento compulsório de patentes no Brasil, decorrente da não-exploração local do produto, alegando ser o artigo 68 da Lei 9.279/96 inconsistente com os artigos 27.1 e 28.1 do TRIPS, no que foram secundados pela União Européia, que em 20 de junho de 2000 ingressou com pedido de "Joint Consultation". A 9 de janeiro de 2001 pediram a abertura de um painel contra o Brasil na OMC, que seria retirado em julho de 2001. A desistência se deu porque Estados Unidos e Brasil aceitaram transferir suas divergências para o plano bilateral, evitando assim, os procedimentos comuns à resolução de conflitos. Embora o questionamento não envolvesse explicitamente a indústria farmacêutica, seu efeito teria implicação direta para as políticas de saúde pública, que se refletiria na produção nacional de medicamentos anti-retovirais, necessários ao tratamento do HIV.

Em novembro de 2001, os EUA se juntam ao grupo liderado por Brasil e Índia, formado por 51 países, para aprovar a resolução da OMC, conhecida como Declaração de Doha, que autorizou a licença compulsória nos moldes do artigo 31, f do TRIPS (artigo 71 da Lei 9.279/96).

Como conseqüência da Declaração de Doha, o impacto da entrada em vigor do TRIPS ${ }^{34}$ parece ter sido atenuado por uma interpretação solidária da decisão do Conselho do TRIPS de 30 de agosto de 2003 (WT/L/540) ${ }^{35}$. Essa deliberação permite que qualquer membro exporte produtos farmacêuticos produzidos sob licença compulsória, dentro dos termos por ela fixados, e permite, por via de conseqüência, a importação desses produtos, mediante notificação ao Conselho do TRIPS. A decisão proíbe a reexportação para países que não se enquadrem nas condições estabelecidas. A decisão acaba por flexibilizar o artigo 31, f, do Acordo, permitindo que países subdesenvolvidos ou em desenvolvimento, que tenham efetuado uma licença compulsória, exportem medicamentos para um outro país que teria o direito de exercer a licença, mas não tem condições tecnológicas de produção, conciliando assim a licença compulsória e a transferência de tecnologia.

\footnotetext{
${ }^{34}$ Em janeiro de 2005.

351 September 2003, WTO - General Council Decision of August 30, 2003, on the implementation of Paragrapf 6 of Doha Declaration on TRIPS and Public Health.
}

Revista Brasileira de Direito Internacional, Curitiba, v.4, n.4, jul./dez.2006 
Vale lembrar que a Índia perdeu um paine $\left.\right|^{36}$ requerido pelos EUA ${ }^{37}$ em $1996^{38}$, por não ter cumprido a determinação do TRIPS ${ }^{39}$ de aceitar, a partir de janeiro de 1995, a requisição de direitos exclusivos de comercialização ${ }^{40}$ de produtos farmacêuticos. Essa era uma obrigação decorrente de uma norma transitória estabelecida pelo artigo 65 do TRIPS para todos os membros da OMC que à época ainda não protegiam através de patentes os produtos farmacêuticos. A Índia acabou sendo um dos últimos membros da OMC a adotar essas medidas ${ }^{41}$, uma vez que nesse país, assim como no Brasil ${ }^{42}$, os tratados internacionais não são de aplicação imediata. No caso indiano, o presidente da Índia promulgou em 31 de dezembro a Patentes Ordinace que emendava o Patents Act de 1970, e cumpria com o disposto no TRIPS, garantido o direito de patente sobre os produtos farmacêuticos (artigo 70.8 (a)), garantido direitos exclusivos de comercialização aos referidos produtos (artigo 70.9). Esta Ordinace foi emitida pelo presidente no exercício dos poderes conferidos a ele pelo artigo 123 da constituição indiana, que permite ao presidente legislar quando o parlamento (uma ou as duas casas) não estiver em sessão, cumprido requisitos de urgência e necessidade, um espécie de medida provisória. Essa Ordinace entrou em vigor em 1 de janeiro de 1995 e durou até 26 de março daquele ano, uma vez que esse tipo de lei deixa de vigorar seis semanas após 0 inicio das atividades parlamentares. Durante 0 período em que a Ordinace vigorou, 125 pedidos de patentes foram recebidos e arquivados.

O governo tentou aprovar no Parlamento uma Patents Bill para dar efeito permanente a medidas trazidas pela Ordinace, mas, no meio do processo, o Parlamento foi dissolvido, e nessa época expirou a validade da Ordinace. Ou seja, a Índia chegou a ter uma legislação protetora de patentes de fármacos, e, ao deixar de ter, foi diretamente questionada na OMC. É muito

\footnotetext{
${ }^{36}$ Segundo o painel, a Índia não cumpriu as obrigações dos artigos 70.8(a), 63 (1) e (2) e 70.9 do TRIPS.

${ }^{37}$ A Comunidade Européia ingressou no painel como terceira parte.

${ }^{38} \mathrm{O}$ pedido de consulta que deu origem à disputa ocorreu em 2 de julho de 1996 e o painel foi estabelecido em 20 de novembro daquele ano.

${ }^{39}$ Violação dos artigos $63,64,70.8$ e 70.9 do TRIPS.

${ }^{40}$ Que na prática são muito similares aos direitos decorrentes de uma patente.

${ }^{41}$ Em 1999.

${ }^{42}$ Com as exceções trazidas pela Emenda Constitucional 45.
}

Revista Brasileira de Direito Internacional, Curitiba, v.4, n.4, jul./dez.2006 
provável que o mesmo aconteça com o Brasil caso volte atrás na questão das patentes de fármacos.

Extrai-se desse fato, o que pode acontecer ao Brasil caso atualmente resolva não garantir a patente de medicamentos.

A caracterização de uma violação do TRIPS teria um custo incalculável para todos os setores da economia do país, seja pelas retaliações, no imediato, seja por uma denúncia e conseqüente saída da OMC, mais adiante. No âmbito dessa organização, a reação contra o Brasil observaria naturalmente diversos estágios antes de se chegar à denúncia. Várias instâncias de discussão, na forma de pedidos de consultas e painéis, precederiam as retaliações. $O$ custo das consultas e dos painéis em si já seria alto para o Brasil; em seguida, a imposição de retaliações seria certa. E é de recordar que as retaliações não precisam dirigir-se ao setor da economia no qual ocorreu a violação, podendo afetar toda a economia nacional, nos mais diversos setores, prejudicando a população como um todo, não apenas para os portadores de HIV.

Por fim, a exclusão da OMC representaria completo retrocesso, pois lançaria a economia nacional na barbárie de um comércio internacional globalizado e sem lei. A OMC é justamente o resultado de longo esforço internacional para estabelecer uma área de regramento das trocas internacionais, um escudo contra a selvageria. O Brasil tem se beneficiado da adesão à $\mathrm{OMC}$, como provam suas vitórias nos últimos anos em relação ao aço, algodão e açúcar, às quais logo se acrescentará a redução dos subsídios aos produtos agrícolas por parte dos países do Hemisfério Norte. Deixar a OMC seria jogar por terra inclusive esses êxitos e anular as perspectivas de futuras conquistas, que o Brasil e outros países menos desenvolvidos podem obter em disputas na OMC, dando-Ihes direito de promoverem retaliações contra os países infratores, freqüentemente países desenvolvidos.

Mesmo fora do âmbito da OMC, a aprovação de tal projeto, causaria insegurança jurídica internacional ao Brasil, em relação a outros acordos dos quais o país é signatário.

Quanto à situação dos portadores de HIV, ficaria em risco, além de tudo o que o já se conseguiu, o prestígio do Brasil como campeão na luta 
contra a epidemia de AIDS. Ficariam empanadas vitórias como a resolução aprovada pela ONU em abril de 2001, proposta pelo Brasil, pela qual o acesso aos remédios passava a ser considerado um direito humano; também a resolução obtida na Organização Mundial da Saúde - $\mathrm{OMS}^{43}$, que resultou na já citada decisão do Conselho do TRIPS de 30/08/2003 (WT/L/540). Prejudicaria também alternativas recentes, que beneficiam não só o Brasil como outros países em desenvolvimento, como a Rede de Transferência de Tecnologia ${ }^{44}$.

Ademais, a decisão ainda poderia ser contestada pelas partes prejudicadas (laboratórios detentores de patentes) internamente, podendo até mesmo ser declarada inconstitucional, após, é claro, muitos anos e reais gastos na disputa, o que acabaria por gerar insegurança até mesmo entre aqueles que seriam beneficiários da nova lei (usuários dos medicamentos e produtores locais).

Observaram Subramanian e Watal ${ }^{45}$ : "If IP rights, once conferred trough domestic legislation and pursuant to an act of the parliament, are withdrawn, this can be challenges by the affected parties in the domestic courts as being illegal or even unconstitutional."

O deputado autor do projeto diz que se baseou numa lei sul-africana para elaborá-lo. Cabe lembrar que a África do Sul só conseguiu estabilizar o número de pessoas contaminadas pelo HIV em 1999, basicamente impedindo novas contaminações, com um programa chamado $A B C$, sigla em inglês para abstinência - fidelidade - "preservatização" ${ }^{\text {", }}$, ou seja, com base na prevenção. Já aqueles sul-africanos que se encontram infectados não tiveram a mesma sorte dos brasileiros; apenas em 2003 o governo sul-africano começou a

\footnotetext{
${ }^{43}$ No âmbito da Organização Mundial de Saúde, o Brasil conseguiu uma resolução favorável à política de licenciamento compulsório de patentes. O conselho da OMS decidiu enviar carta à OMC, na qual solicitava fosse feita a regulamentação do acordo de Doha, inicialmente prevista para dezembro de 2002, que definiu o acesso aos medicamentos essenciais como uma questão de direitos humanos.

${ }^{44}$ Lançada na XV Conferência Internacional sobre AIDS, em 13 de julho de 2004 em Bancoc, da qual participam Brasil, Rússia, China, Ucrânia, Nigéria e Tailândia. A Rede propõe-se à troca ou transferência de tecnologia sobre fármacos, especialmente os ligados ao tratamento do HIV/AIDS, de forma gratuita entre esses Estados, o que não desrespeita o TRIPS e permite a apropriação de tecnologia.

${ }^{45}$ SUBRAMANIAN, Arvind; WATAL, Fayashree. Can TRIPS serve as an enforcement device for developing countries in the WTO? Journal of International Economic Law, Oxford University Press, p. 403-416, 2000.

${ }^{46}$ Condomize.
}

Revista Brasileira de Direito Internacional, Curitiba, v.4, n.4, jul./dez.2006 
distribuir gratuitamente anti-retrovirais, e apenas para mulheres grávidas, através de um programa inspirado no modelo brasileiro. A África do Sul envia regularmente profissionais de Saúde ao Brasil para aprender sob nossos métodos de combate a AIDS ${ }^{47}$.

\section{CONSIDERAÇÕES FINAIS}

Diante do exposto pode-se concluir que apesar de bem intencionado, a aprovação do projeto de lei em tela seria desastrosa para o Brasil. A política atual anti-AIDS é um modelo internacional; pode não ser perfeita, mas vem oferecendo tratamento adequado aos portadores do vírus. A aprovação do projeto representaria um golpe para toda a economia e não garantirira melhor condição para os aidéticos. O Governo Brasileiro deveria concentrar seus esforços, como lembra Basso ${ }^{48}$ a continuar o trabalho de implementação dos tratados e convenções relativos à propriedade intelectual e se preparar para explorar melhor as questões relativas à propriedade intelectual e desenvolvimento na 5a Reunião Ministerial que acontecerá em dezembro, assim, como em outros fóruns onde se discutem a matéria, com fins de atingir a capacitação técnica efetiva, e o conhecimento dos instrumentos e ferramentas decorrentes dessas negociações para atingir um melhor nível de desenvolvimento através da propriedade intelectual, usando ela em benefício próprio, e não contra si.

\section{REFERÊNCIAS}

BARRAL, Weber. O Brasil e a OMC. Curitiba: Juruá, 2002.

BASSO, Maristela. O direito internacional da propriedade intelectual. Porto Alegre: Livraria do Advogado, 2000.

Propriedade intelectual na era pós-OMC. Porto Alegre: Livraria do Advogado, 2005.

\footnotetext{
47 SOUTH AFRICA. Towards a ten year review. Synthesis report on implementation of government programmes. Capetown: The Presidency, 2003.

${ }^{48}$ BASSO, Maristela. O direito internacional da propriedade intelectual. Porto Alegre: Livraria do Advogado, 2000. p. 107.
}

Revista Brasileira de Direito Internacional, Curitiba, v.4, n.4, jul./dez.2006 
BRASIL. Decreto Lei no 30, de 15 de dezembro de 1994. Dispõe sobre o Acordo TRIPS ou Acordo ADPIC. [Online]. Disponível em:

<http://www.tralac.org/scripts/content.php?id=1033>. Acesso em: nov. 2006.

. Câmara dos Deputados. Projeto de Lei no 22, de 2003. [Online].

Disponível em: <http://www.abiaids.org.br/media/pl\%202203.pdf>. Acesso em: nov. 2006.

. Presidência da República. Lei no 9.279, de 14 de maio de 1996.

[Online]. Disponível em:

<https://www.planalto.gov.br/ccivil_03/Leis/L9279.htm>. Acesso em: nov. 2006.

CRELIER, Cristiane. Brasil mostra relatório contra pirataria. Gazeta Mercantil, Caderno A, São Paulo, p. 12, 31 ago. 2005.

CRUZ, Ana Santa; SABOIA, Juliana. O Brasil domou a AIDS. Revista Veja, São Paulo, n. 28, fev. 2001.

GRAU-KUNTZ, Karin. Dignidade humana e direito de patentes: sobre 0 problema do acesso a medicamentos. In: CARVALHO, Patrícia Luciane. (Coord.). Propriedade intelectual: estudos em homenagem à professora Maristela Basso. Curitiba: Juruá, 2005.

LA ROCHE, Marie-Catherine de; CIRENZA, Fernanda. AIDS: Esperança e agonia. Revista Marie Claire, São Paulo, p. 90-93, 2003.

LÚCIO, Leandro Araújo (Org.). O Brasil e a OMC: a quebra de patentes de medicamentos contra a AIDS. In: PIMENTEL, Luiz Otávio. Direito Internacional e da Integração. Florianópolis: Fundação Boiteux, 2003.

MERCADANTE, Araminta; MAGALHÃES, José Carlos (Coord.). Solução e prevenção de litígios internacionais. Rio de Janeiro: Forense, 2003. v. 3.

O ESTADO DE SÃO PAULO, 24 jun. 2005.

. O preço da bravata. Editorial. 13 jun. 2005.

. Propriedade intelectual. Editorial. 25 jun. 2005.

O GLOBO, 21 dez. 2004.

. Laboratórios duvidam de que Brasil consiga quebrar patentes.

[Online]. Disponível em: <http://www.oglobo.com/serviços>. Acesso em: 21 dez. 2004.

Revista Brasileira de Direito Internacional, Curitiba, v.4, n.4, jul./dez.2006 
ONGS cobram do Brasil licença compulsória para mediamentos de AIDS anunciada em março. [Online]. Disponível em: <http://www.msr.org.br/noticia>. Acesso em: 17 jul. 2005.

PORFÍRIO, Fernando. Justiça condena laboratório indiano por quebra de patente. Revista Consultor Jurídico, 22 set. 2005.

MÉDICOS sem fronteiras. [Online]. Disponível em: <http://www.msf.org.br>. Acesso em: 17 jul. 2005.

BS2 Saúde. [Online]. Disponível em: <http://www.maringasaude.com.br>. Acesso em: 07 jan. 2004.

SOUTH AFRICA. Towards a ten year review. Synthesis report on implementation of government programmes. Capetown: The Presidency, 2003.

SUBRAMANIAN, Arvind; WATAL, Fayashree. Can TRIPS serve as an enforcement device for developing countries in the WTO? Journal of International Economic Law. Oxford University Press, p. 403-416, 2000.

VARGAS, Fábio Aristimunho. O regime internacional de proteção do acesso a medicamentos: um enfoque social. In: CARVALHO, Patrícia Luciane. (Coord.). Propriedade intelectual: estudos em homenagem à professora Maristela Basso. Curitiba: Juruá, 2005.

UNIVERSIDADE DE SÃO PAULO. [Online]. Disponível em: $<$ http://www2.usp.br/canalacontece/frame.php?canal $=. . /$ canalacontece/\&conteudo=../busca. php?key=compulsório $>$. Acesso em: 10 dez. 2004. 